\title{
The Influence Mechanism of
}

\section{Employee-Oriented Human Resource Management on Employees' Proactive Behavior}

\author{
Jianfei Pan \\ Management School, Shanghai University, Shanghai, China \\ Email: panjianfei686@163.com
}

How to cite this paper: Pan, J.F. (2018) The Influence Mechanism of Employee-Oriented Human Resource Management on Employees' Proactive Behavior. Open Access Library Journal, 5: e4695.

https://doi.org/10.4236/oalib.1104695

Received: May 30, 2018

Accepted: July 14, 2018

Published: July 17, 2018

Copyright $\odot 2018$ by author and Open Access Library Inc.

This work is licensed under the Creative Commons Attribution International License (CC BY 4.0).

http://creativecommons.org/licenses/by/4.0/

\section{(c) (i) Open Access}

\begin{abstract}
This study attempts to explore the incentive mechanism of employees' proactive behavior in the context of advocating and practicing socially responsible human resource management (SR-HRM). By conducting theoretical analysis and hypothesis, this study focuses on the influence of employee-oriented human resource management (EOHRM) on employees' proactive behavior, and then assumes the role of employees' perceived insider status and learning goal orientation.
\end{abstract}

\section{Subject Areas}

Human Resource Management

\section{Keywords}

Employee-Oriented HRM, Proactive Behavior, Perceived Insider Status, Learning Goal Orientation

\section{Background and Motivation}

With the continuous attention of corporate social responsibility (CSR), enterprises in the theory and practice of human resource management have begun to advocate and practice the concept of CSR. However, corporate social responsibility for a long time has discussed corporate social responsibility to customers, consumers, government and the influence of the environment and other stakeholders, less involved in corporate social responsibility to employees or impact study of the internal stakeholders. As one of the key stakeholders of the enterprise, employees are an important resource of the enterprise, emphasizing and attaching importance to the rights and needs of employees within the enterprise and becoming one of the important objectives of human resource management 
[1]. Shen and Zhu (2011) [2] developed the term SR-HRM to capture CSR policies and practice directed at the organization's stakeholders. The concept of EOHRM originates from the CSR and HRM literature. EOHRM at the macro level involves corporate social responsibility (CSR) activities that directly address employees' personal and family needs that are above and beyond legal requirements, and it is thus regarded as an important type of socially responsible HRM (Shen \& Zhu, 2011) [2]. EOHRM should have positive effects on employees, but until now no research has explored this issue. Given the global concern with CSR and employees' rights, wellbeing and personal and developmental needs, the effects of SR-HRM on employee attitudes and behaviors remain a legitimate pursuit for the HRM research [3].

As a result of increased pressure for flexibility and innovation and career models that require greater self-direction, scholars nowadays stress the importance of proactive employee behavior (e.g., Parker, Williams, \& Turner, 2006) [4]. Organizations need flexible and responsive employees who approach work proactively by showing initiative without the constant need for close supervision (Crant, 2000; Fay \& Frese, 2001; Parker, 2000) [5] [6] [7]. The increasing pressure on employees to be proactive at work is also mentioned in other areas of research. For example, career researchers argue that individuals should rely less on their organizations and instead take initiative themselves when it comes to their personal and career development (e.g., Morrison, 2002; Seibert, Kraimer, \& Crant, 2001) [8] [9]. Research on employees' proactive behavior is, therefore, of both theoretical and practical importance. This study focuses on the influence of employee-oriented human resource management on the employees' proactive behavior.

\section{Theoretical Analysis and Hypothesis}

\subsection{The Relationship between Employee-Oriented HRM and Employees' Proactive Behavior}

Employee-oriented HRM addresses employee's personal and family needs that are above and beyond legal requirements. For example, it involves providing employees with adequate training and development opportunities, providing feedback, and introducing flexible working arrangements. It also includes encouraging employees in decision-making processes by adopting workplace democracy and power sharing. The research shows that socially responsible human resource management (SR-HRM) actively affects task performance and extra-role helping behavior (Shen \& Benson, 2016) [10]. Research shows that the three dimensions of SRHRM may operate via different mechanisms to influence employee attitudes and behaviors. For example, Shen and Zhu (2011) [2] found that the three dimensions of SRHRM have different relationships with organizational commitment. Similarly, Newman, Miao, Hofman and Zhu (2015) [11] found that these three dimensions tend to influence OCB in different manners. Both studies raise the necessity to examine the dimensions of SRHRM separately. Hu and Jiang (2016) [3] found that Employee-oriented HRM on employee 
voice behavior has positive effect, and the study of the more specific employee guide contains the content of the human resources management, and the concept plays an important role for later research.

However, there is little research on the relationship between employee-oriented HRM and proactive behavior. Therefore, in this study, we focus on the impact of employee-oriented HRM on employees' proactive behavior. We want to know how EOHRM affects employees' proactive behavior. What theory can explain it? Taken together, we propose:

1) Hypothesis 1: EOHRM is positively related to proactive behavior.

\subsection{Perceived Insider Status as a Mediator in the EOHRM-Proactive Behavior Relationship}

Advocacy and practice of employee-oriented HRM to improve employees' perceived organizational membership, not only can make employees needs fulfill, and improve the mattering of staff awareness, but also can make the staff belong. The needs fulfillment and the mattering perception are important factors for employees to feel a sense of belonging. This research focuses on the perceived insider status of an important component of belonging. The definition of perceived insider status was the extent to which employees perceive themselves to be organization insiders (versus outsiders) (Stamper \& Masterson, 2002) [12]. Yin Jun said perceived insider status concept is closely related to Chinese traditional culture, under the situation of China, and when employees perceive themselves as members of the organization's, will be to identity the master exists in organization, and shows more conducive behavior to the organization [13]. Li, Zheng and Liu (2017) [14] based on the theory of resource preservation, believe that perceived insider status concept as a rich psychological resource enables employees to actively devote themselves to their work. Zhao and Tang (2015) [15] through the literature the literature research of the consequences of perceived insider status variables summarized relevant conclusion, believe that there is a research perceived insider status plays a positive role on employees' individual behavior. Ding, Chen and CAI (2017) [16] have found that the perceived insider status has a positive influence on proactive behavior. Only when employees have a good sense of belonging and tolerance in the organization can they consciously motivate their initiative, enthusiasm and proactive in their work to make more proactive behaviors.

2) Hypothesis 2: EOHRM is positively related to proactive behavior.

3) Hypothesis 3: Perceived insider status is positively related to perceived insider status.

4) Hypothesis 4: Perceived insider status mediates the relationship between EOHRM and proactive behavior.

\subsection{The Moderating Role of Learning Goal Orientation}

Three goal orientations are distinguished in the literature: learning, performance-prove, and performance-avoid (e.g., VandeWalle, 1997; VandeWalle, 


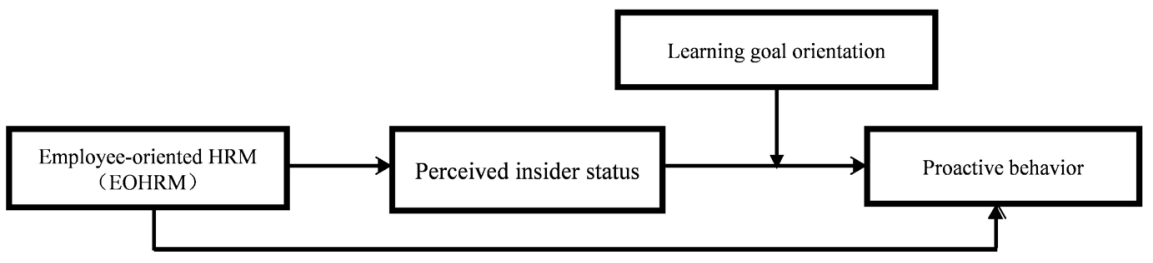

Figure 1. Proposed research model.

Cron, \& Slocum, 2001) [17] [18]. Individuals high on learning goal orientation aim primarily at acquiring new skills and knowledge from work tasks. Previous research links learning goal orientation to willingness to work hard and the belief that greater effort leads to success, and it shows individuals high on learning orientation are proactive in enhancing self-development (Porath \& Bateman, 2006) [19]. People high on learning orientation are expected to perceive engaging in proactive behavior as a worthwhile potential opportunity for learning (Farr, Hoffmann, \& Ringenbach, 1993) [20]. Consistently, learning goal orientation was positively related to general proactive behaviour measures (Parker \& Collins, 2010; Porath \& Bateman, 2006) [19] [21]. Xu and Qu (2015) [22] points out that individuals high on learning goal orientation willing to acquire knowledge and skills by learning, improve their ability to do work. At the same time, they can effectively set goals by anticipating events and changes in the future. Such individuals are more likely to engage in complex and challenging work. When faced with difficulties, they are willing to give extra effort to explore new ways of thinking and proposing deeper creative solutions. When this kind of difficulty can't be solved through their own efforts, they will create possible opportunities to present problems to others in the team and find solutions to problems. Therefore, the employees high on learning goal orientation will show more proactive behaviors.

Although employees high on learning goal orientation will show more proactive behaviors, but when Enterprise implement the employee-oriented HRM, to what extent is learning goal orientation influence the relationship between perceived insider status and proactive behavior? The impact of employer-oriented HRM on employees' proactive behavior will be more positive when the employees high on learning goal orientation?

5) Hypothesis 5: Learning goal orientation moderates the relationship between perceived insider status and proactive behavior, such that this relationship is stronger among employees with higher learning goal orientation

6) Hypothesis 6: Learning goal orientation the indirect relationship between EOHRM and proactive behavior via perceived insider status, such that this indirect relationship is stronger among employees with higher learning goal orientation (Figure 1).

\section{References}

[1] Shen, J. (2011) Developing the Concept of Socially Responsible International Hu- 
man Resource Management. International Journal of Human Resource Management, 22, 1351-1363. https://doi.org/10.1080/09585192.2011.559104

[2] Shen, J. and Zhu, C.J. (2011) Effects of Socially Responsible Human Resource Management on Employee Organizational Commitment. International Journal of $\mathrm{Hu}$ man Resource Management, 22, 3020-3035.

https://doi.org/10.1080/09585192.2011.599951

[3] Hu, X. and Jiang, Z. (2016) Employee-Oriented HRM and Voice Behavior: A Moderated Mediation Model of Moral Identity and Trust in Management. International Journal of Human Resource Management, 24, No. 14. https://doi.org/10.1080/09585192.2016.1255986

[4] Parker, S.K., Williams, H.M. and Turner, N. (2006) Modeling the Antecedents of Proactive Behavior at Work. Journal of Applied Psychology, 91, 636.

https://doi.org/10.1037/0021-9010.91.3.636

[5] Crant, J.M. (2000) Proactive Behavior in Organizations. Journal of Management, 26, 435-462. https://doi.org/10.1177/014920630002600304

[6] Fay, D. and Frese, M. (2001) The Concept of Personal Initiative: An Overview of Validity Studies. Human Performance, 14, 97-124.

https://doi.org/10.1207/S15327043HUP1401_06

[7] Parker, S. (2000) From Passive to Proactive Motivation: The Importance of Flexible Role Orientations and Role Breadth Self-Efficacy. Applied Psychology, 49, 447-469. https://doi.org/10.1111/1464-0597.00025

[8] Morrison, E.W. (2002) Newcomers' Relationships: The Role of Social Network Ties during Socialization. Academy of Management Journal, 45, 1149-1160. https://doi.org/10.5465/3069430

[9] Seibert, S.E., Kraimer, M.L. and Crant, J.M. (2001) What Do Proactive People Do? A Longitudinal Model Linking Proactive Personality and Career Success. Personnel Psychology, 54, 845-874. https://doi.org/10.1111/j.1744-6570.2001.tb00234.x

[10] Shen, J. and Benson, J. (2016) When CSR Is a Social Norm: How Socially Responsible Human Resource Management Affects Employee Work Behavior. Journal of Management, 42, 1723-1746. https://doi.org/10.1177/0149206314522300

[11] Newman, A., Nielsen, I. and Miao, Q. (2015) The Impact of Employee Perceptions of Organizational Corporate Social Responsibility Practices on Job Performance and Organizational Citizenship Behavior: Evidence from the Chinese Private Sector. The International Journal of Human Resource Management, 26, 1226-1242. https://doi.org/10.1080/09585192.2014.934892

[12] Masterson, S.S. and Stamper, C.L. (2003) Perceived Organizational Membership: An Aggregate Framework Representing the Employee-Organization Relationship. Journal of Organizational Behavior, 24, 473-490. https://doi.org/10.1002/job.203

[13] Yin, J., Wang, H. and Huang, M.P. (2012) Empowering Leadership Behavior and Perceived Insider Status: The Moderating Role of Organization-Based Self-Esteem. Acta Psychologica Sinica, 44, 1371-1382. https://doi.org/10.3724/SP.J.1041.2012.01371

[14] Li, Y.P., Zheng X., Liu, Z., et al. (2017) The Effect of Perceived Insider Status on Employee Voice Behavior: A Study from the Perspective of Conservation of Resource Theory. Chinese Journal of Management, 14, 196-204.

[15] Zhao, H., Tang, X., et al. (2015) A Literature Review of Perceived Insider Status. Foreign Economics \& Management, 37, 56-65.

[16] Ding, D.R., Chen, W.M. and Cai, R.L. (2017) The Effects of Cognition of Insider' 
Status on Proactive Behavior: The Mediating Effect of Psychological Capital and the Moderating Effect of Inclusive Leadership. Journal of Central University of Finance \& Economics, No. 4, 81-89.

[17] Vandewalle, D. (1997) Development and Validation of a Work Domain Goal Orientation Instrument. Educational \& Psychological Measurement, 57, 995-1015. https://doi.org/10.1177/0013164497057006009

[18] Vandewalle, D. (2001) Goal Orientation: Why Wanting to Look Successful Doesn't Always Lead to Success. Organizational Dynamics, 30, 162-171. https://doi.org/10.1016/S0090-2616(01)00050-X

[19] Porath, C.L. and Bateman, T.S. (2006) Self-Regulation: From Goal Orientation to Job Performance. Journal of Applied Psychology, 91, 185-192. https://doi.org/10.1037/0021-9010.91.1.185

[20] Farr, J.L., Hofmann, D.A. and Ringenbach, K.L. (1993) Goal Orientation and Action Control Theory: Implications for Industrial and Organizational Psychology. In: Cooper, C.I. and Robertson, I.T., Eds., International Review of Industrial and Organizational Psychology, Wiley, Chichester, 193-232.

[21] Parker, S.K. and Collins, C.G. (2010) Taking Stock: Integrating and Differentiating Multiple Proactive Behaviors. Journal of Management, 36, 633-662.

https://doi.org/10.1177/0149206308321554

[22] Xu, J.-Z. and Qu, X.-Y. (2015) A Study about the Impact of Personal Goal Orientation on Employees' Proactive Behavior: The Mediating Effect of Psychological Contract and the Moderating Effect of Self-Leadership. 